\title{
Clinical value of urinary retinol-binding protein in ascites due to cirrhosis
}

\author{
YUJING XIA $^{1 *}$, JINGJING LI $^{1 *}$, SAINAN LI $^{1 *}$, TONG LIU $^{1}$, YUQING ZHOU $^{1,2}$, QIN YIN ${ }^{1,2}$, \\ JIANRONG WANG ${ }^{1,3}$, WENXIA LU ${ }^{1,3}$, RONG ZHANG ${ }^{1,3}$, YUANYUAN ZHENG ${ }^{1}$, FAN WANG ${ }^{1}$, \\ JIE LU ${ }^{1}, \mathrm{KAN} \mathrm{CHEN}^{1}$, WEIQI DAI ${ }^{1}$, YINGQUN ZHOU ${ }^{1}$ and CHUANYONG GUO ${ }^{1}$ \\ ${ }^{1}$ Department of Gastroenterology, Shanghai Tenth People's Hospital, \\ Tongji University School of Medicine, Shanghai 200072; ${ }^{2}$ Department of Gastroenterology, \\ The First Affiliated Hospital of Soochow University, Suzhou, Jiangsu 215006; ${ }^{3}$ Department of Gastroenterology, \\ The First Clinical Medical College of Nanjing Medical University, Nanjing, Jiangsu 210029, P.R. China
}

Received October 6, 2015; Accepted July 12, 2017

DOI: $10.3892 /$ etm.2017.5190

\begin{abstract}
The aim of the present study was to explore the clinical value of urinary retinol-binding protein (RBP) level in the prognosis of cirrhotic ascites by assessment of the RBP levels prior to and following ascites treatment. The levels of urinary RBP, urinary microalbumin (mAlb), serum urea nitrogen (urea) and serum creatinine $(\mathrm{Cr})$, and the estimated glomerular filtration rate (eGFR) were measured in 90 patients with cirrhosis and ascites hospitalized in a single institution between May 2011 and January 2012, and in 30 healthy controls. The levels of urinary mAlb, serum urea and serum $\mathrm{Cr}$ were higher in the cirrhotic patients compared with the healthy controls $(\mathrm{P}<0.05)$. Urinary RBP levels were significantly higher and eGFR was significantly lower in the liver cirrhosis group compared with the healthy control group $(\mathrm{P}<0.01)$. Urinary $\mathrm{RBP}$, urinary $\mathrm{mAlb}$, serum urea and serum $\mathrm{Cr}$ increased and eGFR decreased as the severity of the ascites increased $(\mathrm{P}<0.05)$. Urinary RBP was significantly higher in patients whose ascites did not respond or was refractory compared with those in whom it subsided $(\mathrm{P}<0.05)$, exhibiting a gradual increase over time in the former and a gradual reduction over time in the latter group $(\mathrm{P}<0.05)$. Increased urinary RBP and decreased eGFR in the early stage of cirrhosis ascites suggested impaired renal function, which serves a role in the process of ascites
\end{abstract}

Correspondence to: Professor Chuanyong Guo or Dr Yingqun Zhou, Department of Gastroenterology, Shanghai Tenth People's Hospital, Tongji University School of Medicine, 301 Yanchang Road, Shanghai 200072, P.R. China

E-mail: guochuanyong@hotmail.com

E-mail:yqzh02@163.com

*Contributed equally

Key words: cirrhosis, ascites, urinary retinol-binding protein formation. These results indicated that urinary RBP is a sensitive indicator of early renal injury in patients with ascites due to cirrhosis and is closely associated with the progression of cirrhotic ascites.

\section{Introduction}

Cirrhosis is a chronic, progressive, diffuse disease caused by a variety of factors, including hepatitis B virus, alcoholic liver disease and autoimmune liver disease (1-3). Liver cirrhosis mortality increased from $1.54 \%$ of global mortality in 1980 to $1.95 \%$ in 2010 (4). Ascites is a common complication of cirrhosis decompensation. Approximately $50 \%$ of patients with compensated cirrhosis develop ascites within a period of 10 years (5). The emergence of ascites predicts a poor prognosis of decompensated cirrhosis, with a mortality of $15 \%$ after 1 year and $44 \%$ at the 2 year follow-up. (6). In addition, the quality of life of patients with cirrhosis decreases following the formation of ascites and the 5-year survival rate drops to $50 \%$ (7). When ascites progress to refractory ascites, if a liver transplant is not conducted, the prognosis worsens and the 2-year survival rate falls to $35-50 \%$ (8). Treatment of ascites not only improves the quality of life of patients, but also reduces the risk of progression to spontaneous bacterial peritonitis, which is the most common fatal complication of liver cirrhosis (9). An improved understanding of the pathophysiological mechanism for ascites in patients with liver cirrhosis is necessary to improve patient treatment and to assist the use of targeted therapies.

Ascites formation is the result of the combined action of many factors; however, the mechanism underlying the formation of cirrhotic ascites has not been fully elucidated. The formation of ascites is a complex process that involves the liver, kidney, hemodynamics and neuro-hormonal factors. The main pathophysiological theories of ascites formation include the underfill theory, the overfill theory and the peripheral artery expansion theory (10). The underfill theory (11) is a derivation of Starling's liquid equilibrium theory (12), which is based on the balance between the internal and external vessel hydrostatic pressure and colloid osmotic 
pressure. According to this theory, liver cirrhosis leads to increased portal pressure. The increase of portal vein capillary bed hydrostatic pressure and/or the drop of plasma colloid osmotic pressure disrupt the Starling balance of the capillary bed and endovascular liquid spills into the abdominal cavity. However, blocking and congestion reduce circulatory system resistance, and effective renal blood flow is reduced. In addition, ascites formation reduces effective renal blood flow. The activation of the renin-angiotensin-aldosterone system (RAAS), norepinephrine system and arginine vasopressin system then induce the absorption of sodium and water by the renal tubules, further promoting the formation of ascites. Therefore, sodium and water retention is secondary $(13,14)$. The overfill theory (14) is based on the association between portal hypertension and low blood volume. Levy and Wexler (15) suggested that low pressure receptors in the liver send signals to the renal tubules indicating sodium retention. In cirrhotic portal hypertension, liver function changes and high hepatic sinus internal pressure lead to renal sodium retention by neuro-humoral factors (16), and the expansion of blood volume then results in the formation of ascites. The peripheral artery expansion theory (17) states that patients with liver cirrhosis first develop sodium and water retention, followed by the formation of ascites. This theory was first proposed in 1988 by Schrier et al (17), who hypothesized that the formation of cirrhosis-related ascites was preceded by peripheral artery expansion resulting in the activation of vaso-excitor material, including 5-hydroxytryptamine and thromboxane A2, the sodium and water retention system, the sympathetic nerve, RAAS and vasopressin, leading to renal vasoconstriction, sodium and water retention, and ascites formation. The three theories are not completely conflicting, and have the same pathological physiological principles at certain levels; that is, when the body senses that the effective arterial blood volume has decreased, it is able to activate the sympathetic nerve, arginine-vasopressin feedback system and RAAS, resulting in renal vasoconstriction, and increased sodium and water absorption by the renal tubules leading to ascites formation or aggravation. Studies have suggested that renal artery resistance increases significantly in patients with cirrhosis and massive ascites (18-20). Therefore, the process of formation of ascites as a complication of liver cirrhosis involves changes in the functional status of the liver, renal function, circulatory system disorders and neuro-hormonal activation. These findings indicate that renal dysfunction serves an important role in the formation and progression of cirrhotic ascites.

Retinol-binding protein (RBP) is a small protein present at low levels in human urine. The $\sim 90 \%$ of normal serum $\mathrm{RBP}$ that is combined with thyroxine-binding protein is not filtered by the glomeruli, and the $\sim 10 \%$ unbound RBP is absorbed by renal tubules following glomerular filtration $(21,22)$. Urinary RBP level remains relatively stable at a $\mathrm{pH}$ of 4.5 , and is not affected by gender or age $(21,22)$. Urinary RBP is a sensitive marker of early renal tubular function damage, which is increased due to the disabsorption of RBP in the presence of renal tubular damage (23). Current research on urinary RBP in patients with cirrhosis is limited and there is no consensus with regard to its clinical value for the detection of kidney damage in patients with cirrhosis. The aim of the present study was to investigate renal injury
Table I. Characteristics of the control group and the cirrhotic ascites group.

\begin{tabular}{lcc}
\hline Group & Sex (male/female) & Age (years) \\
\hline Control & $10 / 20$ & $44.2 \pm 6.89$ \\
Cirrhotic ascites & $32 / 58$ & $46.6 \pm 7.15$ \\
\hline
\end{tabular}

Age data are expressed as the mean \pm standard deviation.

in patients with liver cirrhosis and ascites, the association between renal injury and ascites classification, and the correlation of urinary RBP with urinary microalbumin (mAlb), serum urea nitrogen (urea), serum creatinine $(\mathrm{Cr})$ and estimated glomerular filtration rate (eGFR). In addition, the association between urinary RBP and the curative effect of treatment was investigated by recording the changes in urinary RBP that occurred following treatment in patients with liver cirrhosis and ascites.

\section{Subjects and methods}

Study subjects. A total of 90 patients with liver cirrhosis and ascites hospitalized in Shanghai Tenth People's Hospital of Tongji University (Shanghai, China) between May 2011 and January 2012 were enrolled in the present study. They all conformed to the standard diagnosis of cirrhosis (24). The exclusion criteria used for the present study was as follows: Patients with diabetes and/or high blood pressure; ascites formed 7-10 days after upper gastrointestinal bleeding; malignant ascites; and ascites were caused by right cardiac insufficiency and renal insufficiency. They were divided into three groups as follows: Mild ascites (ascites only detectable by ultrasound; $n=27$ ), moderate ascites (moderate symmetry of abdominal distension; $n=45$ ) and severe ascites (a large amount of ascites, apparent abdominal distension; $n=18$ ), according to the guidelines of the European Association for the Study of the Liver (EASL) (25). The patients comprised 58 women and 32 men with a mean age of $46.6 \pm 7.15$ years (range, 36-75 years). There were 75 patients with cirrhosis caused by chronic hepatitis B, 10 patients with alcoholic cirrhosis and 5 patients with unexplained liver cirrhosis. A control group was also enrolled in the study, and consisted of 30 healthy subjects including 20 women and 10 men with a mean age of $44.2 \pm 6.89$ years. The study was approved by the ethics committee of the Shanghai Tenth People's Hospital of Tongji University. Written informed consent was obtained from the participants prior to the study.

Methods. The morning urine of the control group was collected and $5 \mathrm{ml}$ of this was used for the measurement of urinary RBP and urinary mAlb. In patients with cirrhosis, 24-h urine samples were collected and $15 \mathrm{ml}$ of each sample was used to measure urinary RBP and urinary mAlb. The urinary RBP (cat. no. E016) and urinary mAlb (cat. no. E038) were measured using ELISA kits (both Nanjing Jiancheng Bioengineering Institute, Nanjing, China). A total of $3 \mathrm{ml}$ 
Table II. Urinary RBP, urinary mAlb, serum urea, serum $\mathrm{Cr}$ and eGFR results.

\begin{tabular}{lcccccc}
\hline Group & $\mathrm{n}$ & $\begin{array}{c}\text { Urinary RBP } \\
(\mathrm{mg} / \mathrm{l})\end{array}$ & $\begin{array}{c}\text { Urinary mAlb } \\
(\mathrm{mg} / \mathrm{l})\end{array}$ & $\begin{array}{c}\text { eGFR } \\
\left(\mathrm{ml} / \mathrm{min} / 1.73 \mathrm{~m}^{2}\right)\end{array}$ & $\begin{array}{c}\text { Serum urea } \\
(\mathrm{mmol} / \mathrm{l})\end{array}$ & $\begin{array}{c}\text { Serum Cr } \\
(\mu \mathrm{mol} / \mathrm{l})\end{array}$ \\
\hline Control & 30 & $0.27 \pm 0.08$ & $12.47 \pm 5.12$ & $100.01 \pm 20.32$ & $5.22 \pm 1.73$ & $82.21 \pm 15.82$ \\
Cirrhotic ascites & 90 & $2.02 \pm 1.03^{\mathrm{a}}$ & $18.56 \pm 6.87^{\mathrm{b}}$ & $70.52 \pm 15.39^{\mathrm{a}}$ & $6.20 \pm 1.93^{\mathrm{b}}$ & $94.45 \pm 17.01^{\mathrm{b}}$ \\
Mild ascites & 27 & $0.91 \pm 0.41^{\mathrm{a}}$ & $13.68 \pm 4.31$ & $77.21 \pm 15.52^{\mathrm{a}}$ & $5.11 \pm 1.51$ & $81.21 \pm 11.31$ \\
Moderate ascites & 45 & $2.21 \pm 0.72^{\mathrm{a}}$ & $17.44 \pm 4.34^{\mathrm{a}}$ & $68.43 \pm 16.52^{\mathrm{a}}$ & $6.49 \pm 2.04^{\mathrm{b}}$ & $90.99 \pm 13.35^{\mathrm{b}}$ \\
Severe ascites & 18 & $3.17 \pm 0.64^{\mathrm{a}}$ & $26.17 \pm 7.58^{\mathrm{a}}$ & $60.11 \pm 13.27^{\mathrm{a}}$ & $7.53 \pm 2.11^{\mathrm{b}}$ & $99.15 \pm 17.51^{\mathrm{b}}$ \\
\hline
\end{tabular}

RBP, retinol-binding protein; mAlb, microalbumin; eGFR, estimated glomerular filtration rate; $\mathrm{Cr}$, creatinine. ${ }^{\mathrm{a}} \mathrm{P}<0.01$ and ${ }^{\mathrm{b}} \mathrm{P}<0.05$ vs. the control group.

Table III. Comparison of urinary RBP, urinary mAlb, serum urea, serum $\mathrm{Cr}$ and eGFR among the cirrhotic ascites groups.

\begin{tabular}{llccc}
\hline Variable & Statistics & $\begin{array}{c}\text { Mild vs. } \\
\text { moderate } \\
\text { ascites }\end{array}$ & $\begin{array}{c}\text { Mild vs. } \\
\text { severe } \\
\text { ascites }\end{array}$ & $\begin{array}{c}\text { Moderate vs. } \\
\text { severe } \\
\text { ascites }\end{array}$ \\
\hline Urinary RBP & Z & -4.25 & -3.46 & -1.17 \\
& P-value & $<0.01$ & $<0.01$ & $<0.05$ \\
Urinary mAlb & Z & -3.92 & -3.59 & -2.11 \\
& P-value & $<0.01$ & $<0.01$ & $<0.05$ \\
eGFR & Z & -3.00 & -2.98 & -1.99 \\
& P-value & $<0.01$ & $<0.01$ & $<0.05$ \\
Serum urea & Z & -3.20 & -2.94 & -1.36 \\
& P-value & $<0.01$ & $<0.01$ & $<0.05$ \\
Serum Cr & Z & -4.31 & -3.07 & -1.152 \\
& P-value & $<0.01$ & $<0.01$ & $<0.05$ \\
\hline
\end{tabular}

RBP, retinol-binding protein; mAlb, microalbumin; eGFR, estimated glomerular filtration rate; $\mathrm{Cr}$, creatinine.

fasting venous blood was collected from the patients each morning; serum urea and serum $\mathrm{Cr}$ were measured using an automatic biochemistry analyzer (7180; Hitachi, Ltd., Tokyo, Japan) and its built-in measuring function in clinical laboratory. eGFR was calculated by Modification of Diet in Renal Disease Study equation (26). Ascites treatment was performed according to the 2010 EASL clinical practice guidelines on the management of ascites in cirrhosis (25). Urinary RBP was then measured 1, 2 and 4 weeks after treatment. After 1 month, ultrasound of the ascites was performed and patients were divided into two groups according to the response of the ascites to treatment as follows: Responsive group (ascites could not be detected by ultrasound after 1 month) and unresponsive group (no evident reduction in ascites after 1 month, or the development of refractory ascites).

Statistical analysis. All data are expressed as the mean \pm standard deviation, and the Student's unpaired t-test was used to analyze differences between two groups. One-way analysis of variance was used to compare data among the groups and Bonferroni correction was used for post hoc tests. The Pearson's test was used for correlation analysis of urinary RBP and urine mAlb with serum urea, serum $\mathrm{Cr}$ and eGFR. $\mathrm{P}<0.05$ was considered to indicate a statistically significant result.

\section{Results}

General information. The present study included 90 patients with liver cirrhosis and 30 healthy individuals. Table I presents the gender composition and the mean age of the two groups in detail, and neither parameter differed significantly between the groups.

Results of the analysis of urinary $R B P$, urinary $m A l b$, serum urea, serum $\mathrm{Cr}$ and $e G F R$ in the liver cirrhosis and control groups. The results presented in Table II show that urinary $\mathrm{RBP}$, urinary mAlb, serum urea and serum $\mathrm{Cr}$ in the liver cirrhosis group were significantly higher compared with those in the control group $(\mathrm{P}<0.05)$. Furthermore, eGFR was significantly lower in the cirrhosis group compared with the control group $(\mathrm{P}<0.01)$. It is evident that renal injury exists in the patients with liver cirrhosis and ascites, and is associated with the formation of the ascites.

Comparison of the results in the mild, moderate and severe ascites groups (Table III and Fig. 1) demonstrated that urinary $\mathrm{RBP}$, urinary $\mathrm{mAlb}$, serum urea and serum $\mathrm{Cr}$ increased and eGFR decreased as the severity of the ascites increased. This indicates that the degree of ascites in liver cirrhosis is proportional to the renal injury.

Correlation of urinary $R B P$ with urinary $m A l b, e G F R$, serum urea and serum $C r$, and of urinary mAlb and eGFR, serum urea and serum $C r$. The correlation of urinary RBP with urinary mAlb, eGFR, serum urea and serum $\mathrm{Cr}$ is presented in Figs. 2-5, respectively, and the correlation of urinary mAlb with eGFR, serum urea and serum $\mathrm{Cr}$ is presented in Figs. 6-8, respectively. The correlation coefficients for the correlation of urinary RBP with urinary $\mathrm{mAlb}$, serum urea, serum $\mathrm{Cr}$ and eGFR were $0.836,0.79,0.826$ and -0.768 , respectively; and those for the correlation of urinary mAlb with urinary RBP, serum urea, serum $\mathrm{Cr}$ and eGFR were $0.836,0.666,0.696$ and -0.794 , respectively. The results of these correlation analyses indicate a significant correlation 


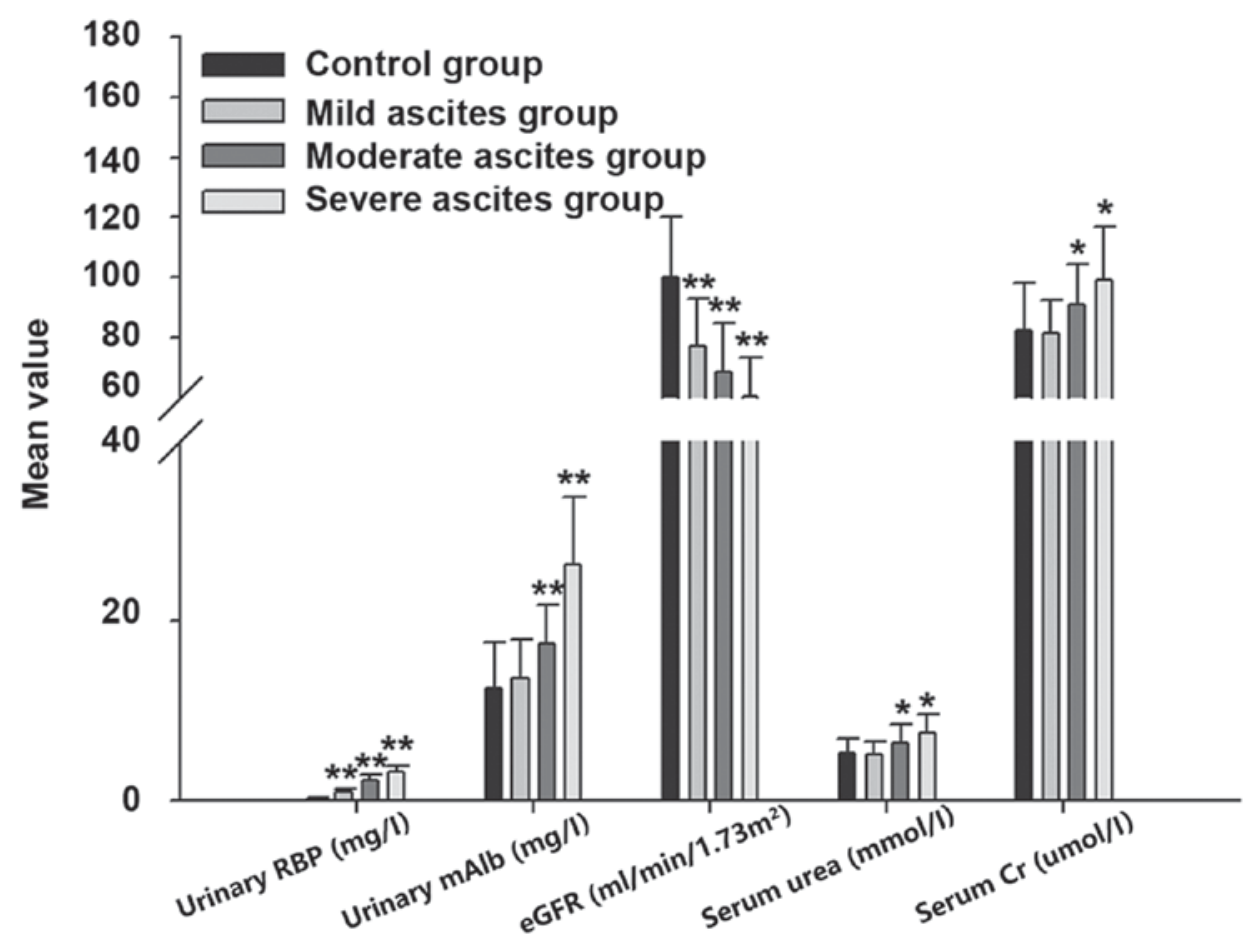

Figure 1. Results of urinary RBP, urinary mAlb, eGFR, serum urea and serum $\mathrm{Cr}$ according to the degree of cirrhotic ascites. ${ }^{*} \mathrm{P}<0.05$ and ${ }^{* *} \mathrm{P}<0.01$ vs. the control group. RBP, retinol-binding protein; mAlb, microalbumin; eGFR, estimated glomerular filtration rate; $\mathrm{Cr}$, creatinine.

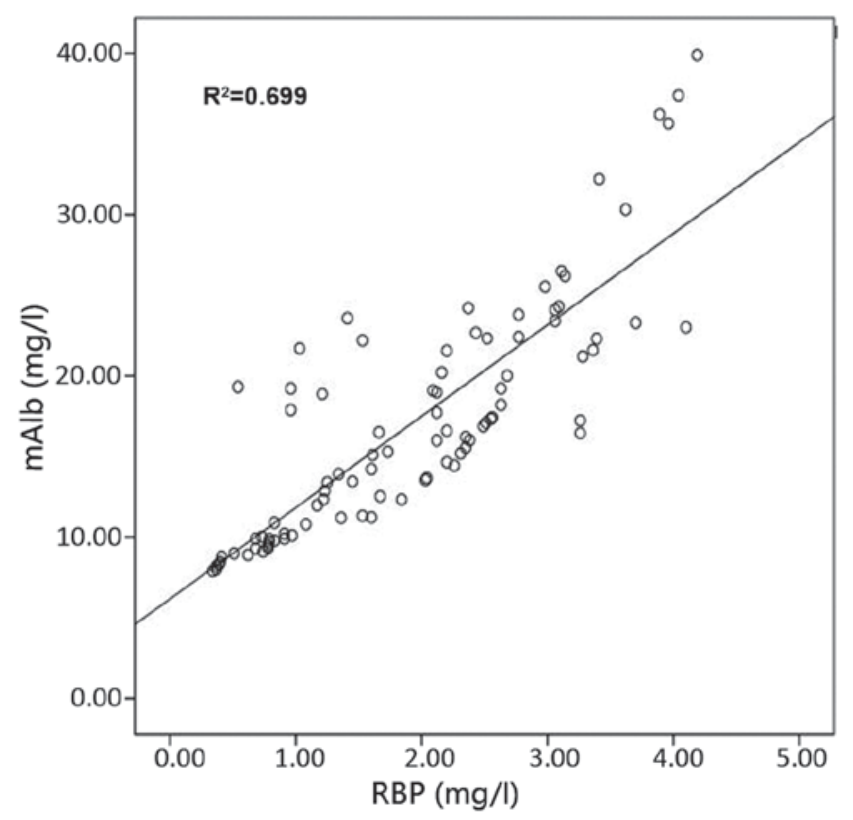

Figure 2. Correlation analysis of urinary RBP and urinary $\mathrm{mAlb}(\mathrm{r}=0.836$, $\mathrm{P}<0.01)$. RBP, retinol-binding protein; mAlb, microalbumin.

of urinary RBP and urine mAlb with serum urea, serum $\mathrm{Cr}$ and eGFR.

Comparison of urinary RBP prior to and following treatment. The results presented in Table IV show that the urinary RBP of the responsive group with cirrhotic ascites was reduced significantly at 2 and 4 weeks after treatment $(\mathrm{P}<0.01)$ and the urinary RBP of the unresponsive group with cirrhotic ascites increased significantly at 2 and 4 weeks after treatment

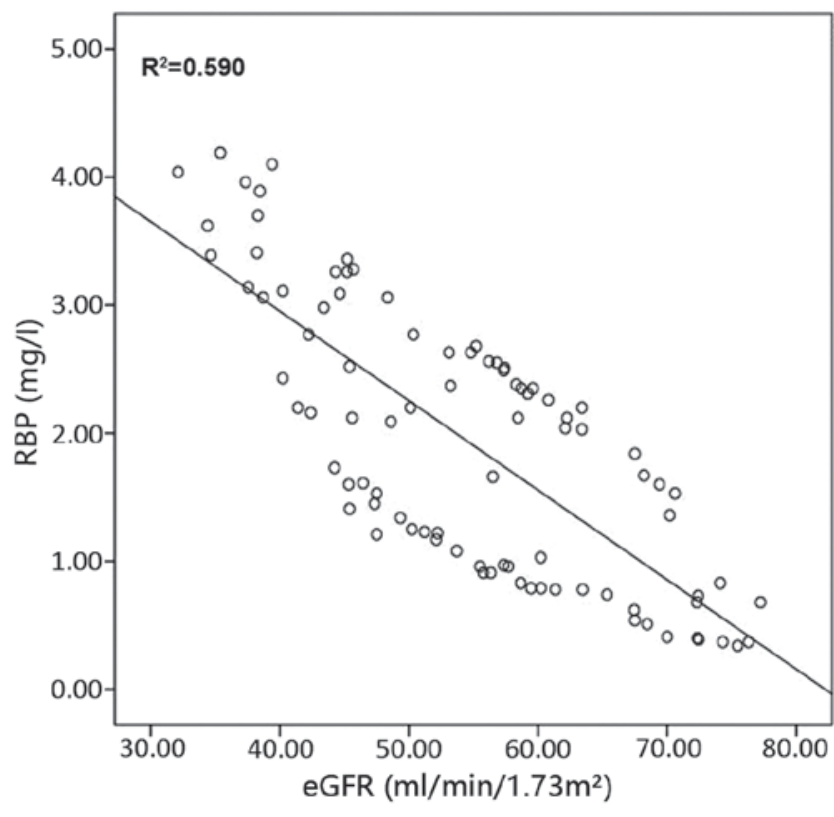

Figure 3. Correlation analysis of urinary RBP and eGFR ( $r=-0.768, \mathrm{P}<0.01)$. $\mathrm{RBP}$, retinol-binding protein; eGFR, estimated glomerular filtration rate.

$(\mathrm{P}<0.01)$ compared with the urinary RBP prior to treatment. The results presented in Fig. 9 show that the urinary RBP level of the unresponsive group with cirrhotic ascites exhibited a gradual increase over time at 1,2 and 4 weeks after treatment $(\mathrm{P}<0.05$ vs. 0 weeks in the unresponsive group), whereas the urinary RBP level of the responsive group with cirrhotic ascites exhibited a gradual reduction over time at 1,2 and 4 weeks after treatment $(\mathrm{P}<0.05$ vs. 0 weeks in the responsive group). 


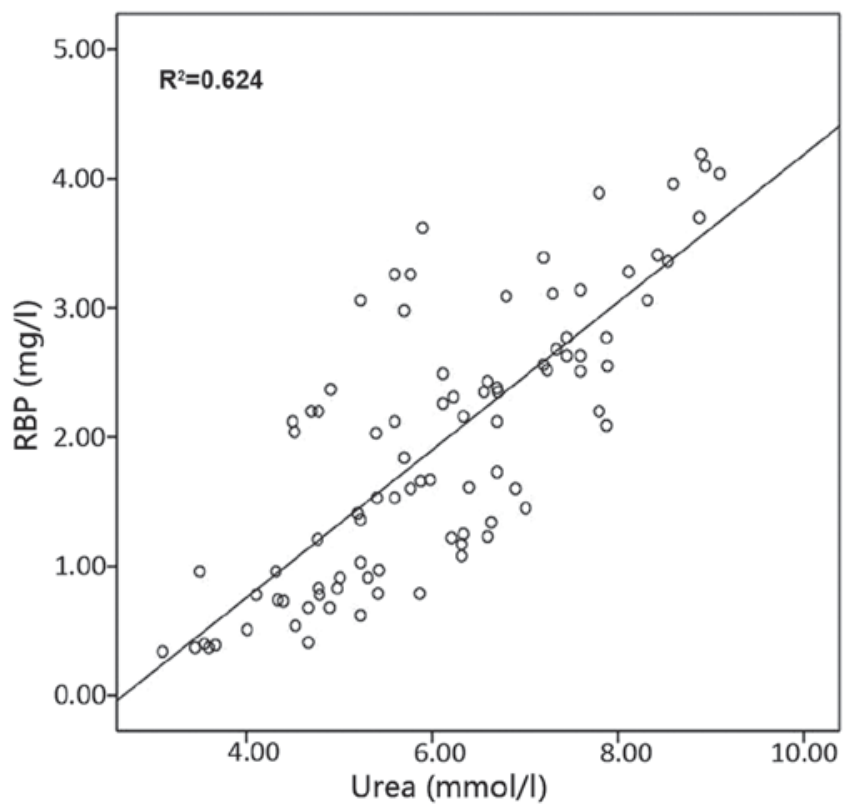

Figure 4. Correlation analysis of urinary RBP and serum urea $(r=0.79$, $\mathrm{P}<0.01)$. RBP, retinol-binding protein.

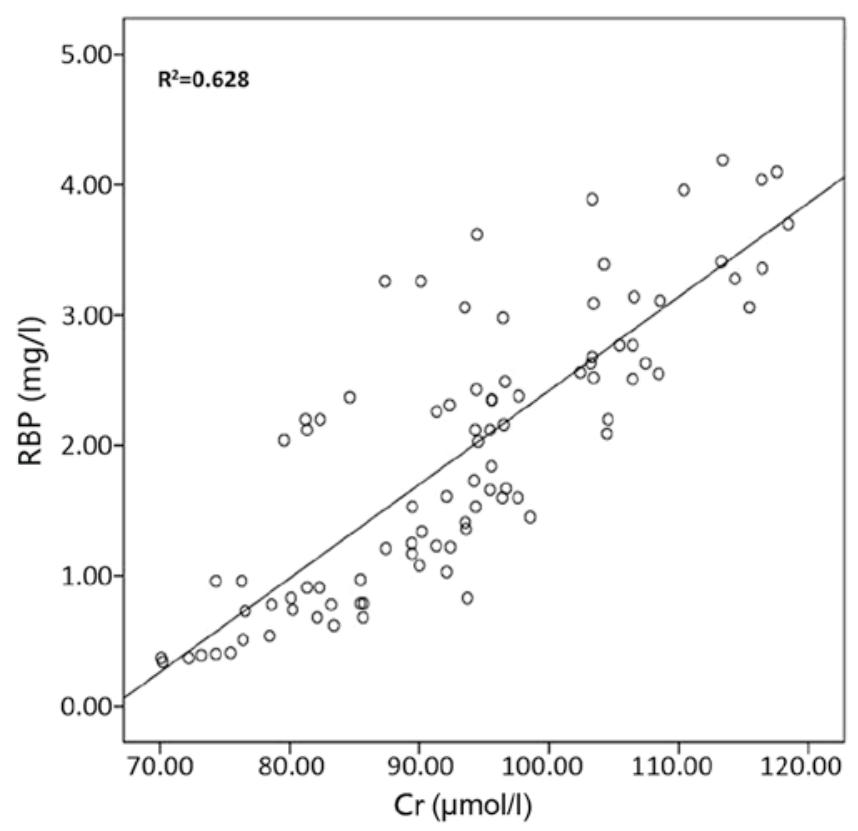

Figure 5. Correlation analysis of urinary RBP and serum $\mathrm{Cr}(\mathrm{r}=0.826$, $\mathrm{P}<0.01)$. RBP, retinol-binding protein; $\mathrm{Cr}$, creatinine.

\section{Discussion}

Ascites is a common complication of liver cirrhosis decompensation, and the prognosis of patients with cirrhosis and ascites is poor, with 2-year mortality rates as high as $50 \%$ (27). Therefore, the treatment of liver cirrhosis-associated ascites is very important. However, there currently are no clinical indicators for use in evaluation of the treatment of this condition. The current study presents some novel findings concerning urinary RBP in cirrhotic ascites.

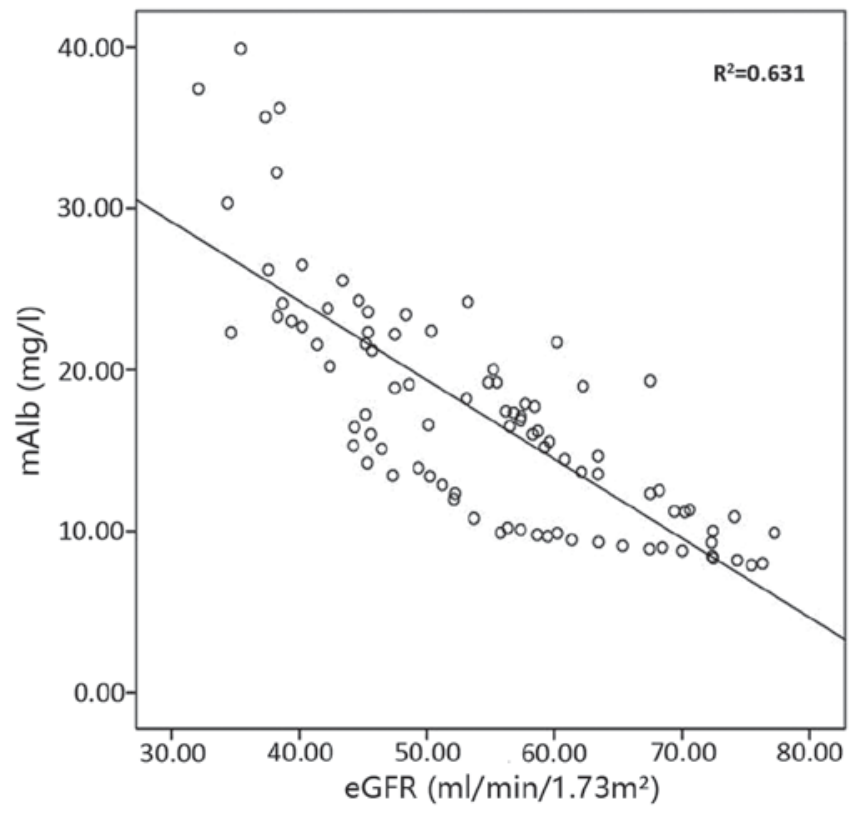

Figure 6. Correlation analysis of urinary mAlb and eGFR $(r=-0.794, \mathrm{P}<0.01)$. mAlb, microalbumin; eGFR, estimated glomerular filtration rate.

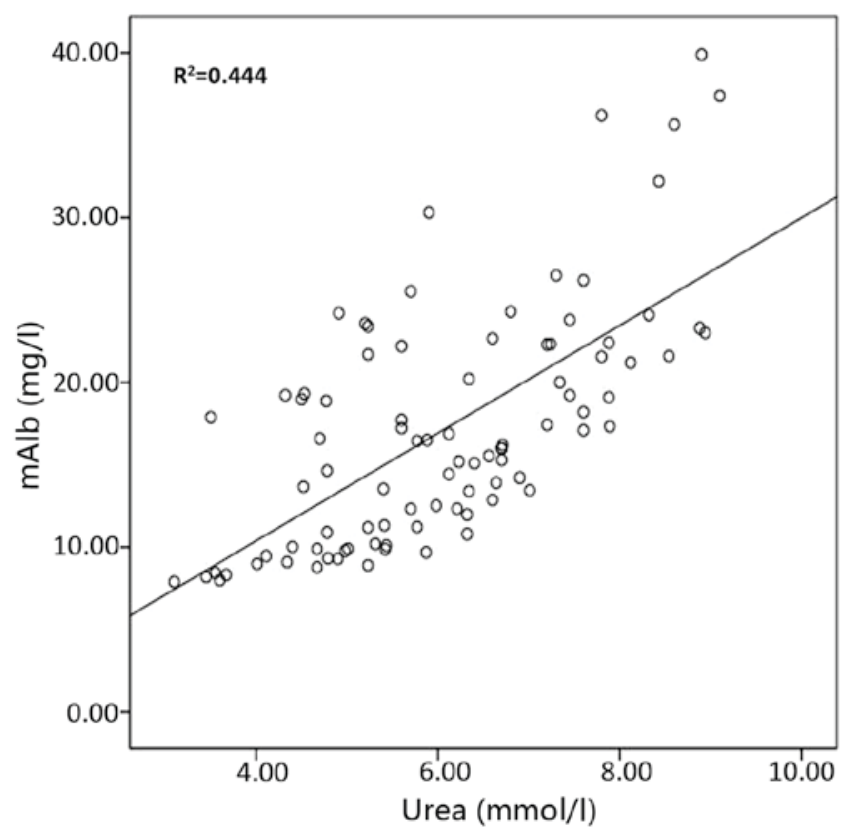

Figure 7. Correlation analysis of urinary mAlb and serum urea $(r=0.666$, $\mathrm{P}<0.01)$. mAlb, microalbumin.

In the group of 90 patients with cirrhotic ascites, urinary $\mathrm{mAlb}$, serum urea and serum $\mathrm{Cr}$ were significantly higher compared with those in the healthy control group $(\mathrm{P}<0.05)$. Furthermore, eGFR was significantly lower in the cirrhosis group compared with the control group $(\mathrm{P}<0.01)$. This indicates that renal injury is present in the patients with liver cirrhosis and ascites, and may be involved in the formation of the ascites. As shown in Fig. 1, urinary RBP, urine mAlb, serum urea and serum $\mathrm{Cr}$ increased and eGFR gradually decreased as the severity of the ascites increased. This suggests that the degree of ascites is proportional to the renal injury. As the 
Table IV. Urinary RBP prior to and following 1,2 and 4 weeks of treatment.

\begin{tabular}{lllll}
\hline & \multicolumn{4}{c}{ Urinary RBP $(\mathrm{mg} / \mathrm{l})$} \\
\cline { 2 - 5 } Group & 0 weeks & 1 week & 2 weeks & 4 weeks \\
\hline
\end{tabular}

Unresponsive $2.53 \pm 0.65 \quad 2.87 \pm 0.89^{\mathrm{a}} \quad 3.48 \pm 0.80^{\mathrm{b}} \quad 3.56 \pm 0.87^{\mathrm{b}}$

Responsive $\quad 1.85 \pm 1.07 \quad 1.35 \pm 0.72^{\mathrm{a}} \quad 0.96 \pm 0.49^{\mathrm{b}} \quad 0.63 \pm 0.34^{\mathrm{b}}$

RBP, retinol-binding protein. ${ }^{\mathrm{a}} \mathrm{P}<0.05$ and ${ }^{\mathrm{b}} \mathrm{P}<0.01$ vs. 0 weeks.

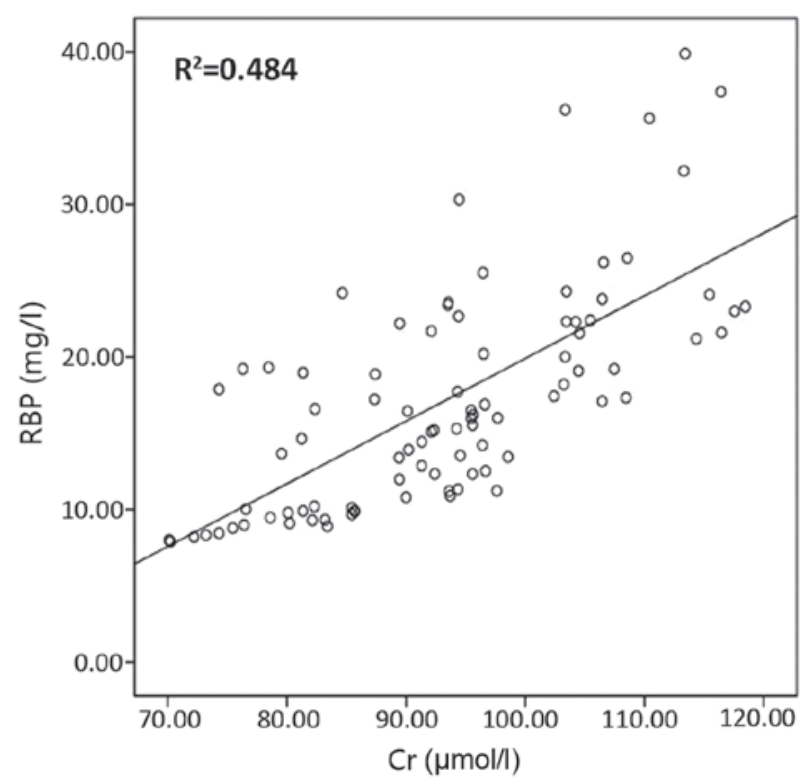

Figure 8. Correlation analysis of urinary mAlb and serum $\mathrm{Cr}(\mathrm{r}=0.696$, $\mathrm{P}<0.01)$. mAlb, microalbumin; $\mathrm{Cr}$, creatinine.

ascites increase in severity, the Child-Pugh classification will also increase; thus, it may be speculated that the Child-Pugh classification is also proportional to the renal injury. The correlation coefficients of urinary RBP with urinary mAlb, serum urea, serum $\mathrm{Cr}$ and eGFR were 0.836, 0.79, 0.826 and -0.768 , respectively. The correlation coefficients of urinary mAlb with urinary RBP, serum urea, serum $\mathrm{Cr}$ and eGFR were $0.836,0.666,0.696$, and -0.794 , respectively, suggesting that urinary RBP and urinary $\mathrm{mAlb}$ are sensitive indicators of renal damage. Urinary RBP showed a good correlation with eGFR, serum urea, and serum Cr. It may be observed that in the mild ascites group, urinary RBP was higher and eGFR was lower compared those in the control group $(\mathrm{P}<0.01)$, whereas urinary $\mathrm{mAlb}$, serum urea and serum $\mathrm{Cr}$ exhibited no difference compared with the control group $(\mathrm{P}>0.05)$, confirming that urinary RBP is a sensitive indicator of early renal damage in liver cirrhosis with ascites. The pathological classification of renal damage during the course of liver cirrhosis is difficult to determine; hepatitis-related IgA nephropathy and glomerular sclerosis are fairly common (28). A previous study including 65 cases with proteinuria $>0.5 \mathrm{~g} /$ day, microscopic hematuria or renal damage of unknown causes (serum creatinine $>1.5 \mathrm{mg} / \mathrm{dl}$ ) in patients with liver cirrhosis observed

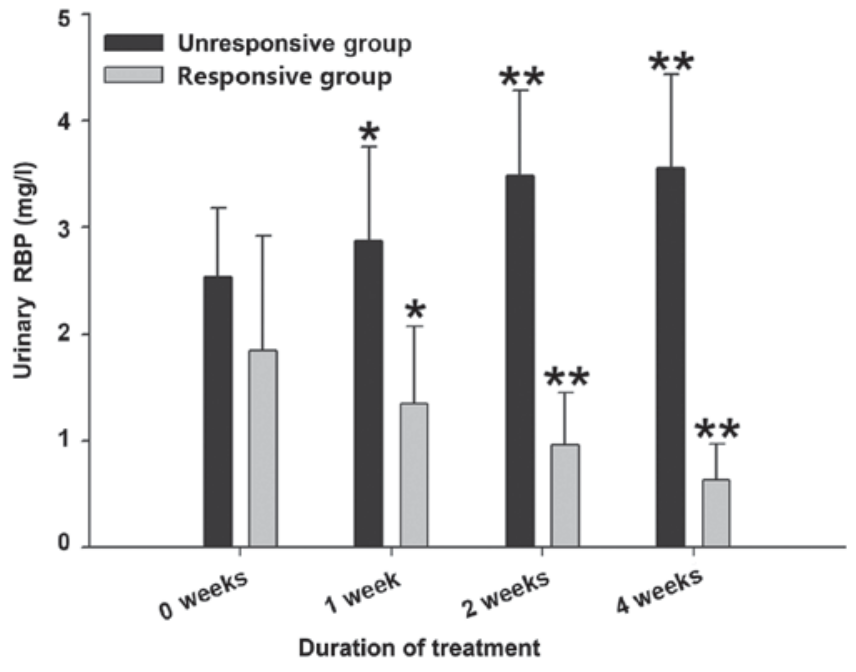

Figure 9. Urinary RBP according to the treatment response of ascites at four time points. ${ }^{*} \mathrm{P}<0.05$ and ${ }^{* *} \mathrm{P}<0.01$ vs. 0 weeks. $\mathrm{RBP}$, retinol-binding protein.

lesions of different degrees in glomerular and non-glomerular structures, including renal blood vessels, renal tubules and renal interstitial fibrosis (29). Therefore, hepatic dysfunction, hemodynamic abnormalities, immune disorders and nervous system dysfunction are closely associated with renal damage in cirrhotic patients.

In the present study, urinary RBP was measured prior to treatment and 1,2 and 4 weeks after treatment, and patients were divided into responsive ascites and unresponsive ascites groups according to the change of the ascites observed following 1 month of treatment. Urinary RBP increased as the severity of the ascites increased, and showed a tendency to increase in the unresponsive group and a tendency to decline in the responsive group. As shown in Table IV, an increase in urinary RBP at 2 and 4 weeks after treatment indicated a poor prognosis of ascites due to cirrhosis, which indicates the potential of urinary RBP to serve as a prognostic indicator in the clinical treatment of patients with liver cirrhosis and ascites.

In summary, urine RBP is a sensitive indicator of early renal damage in liver cirrhosis with ascites, which may be used to monitor the curative effect of treatment, and serve as a clinical indicator to evaluate the prognosis of patients with ascites due to cirrhosis. In addition, the results of the present study may prompt a novel method to study other complications of cirrhosis, including portal hypertension (30), hepatic encephalopathy (31) and hepatocellular carcinoma $(32,33)$.

\section{Acknowledgements}

The present study was supported by the National Natural Science Foundation of China (grant no. 81500466).

\section{References}

1. Sivanathan V, Kittner JM, Sprinzl MF, Weinmann A, Koch S, Wiltink J, Nguyen-Tat M, Marquardt JU, Wörns MA, Zimmermann T, et al: Etiology and complications of liver cirrhosis: Data from a German centre. Dtsch Med Wochenschr 139: 1758-1762, 2014 (In German). 
2. Silva MJ, Rosa MV, Nogueira PJ and Calinas F: Ten years of hospital admissions for liver cirrhosis in portugal. Eur J Gastroenterol Hepatol 27: 1320-1326, 2015.

3. Qua CS and Goh KL: Liver cirrhosis in Malaysia: peculiar epidemiology in a multiracial Asian country. J Gastroenterol Hepatol 26: 1333-1337, 2011.

4. Mokdad AA, Lopez AD, Shahraz S, Lozano R, Mokdad AH, Stanaway J, Murray CJ and Naghavi M: Liver cirrhosis mortality in 187 countries between 1980 and 2010: A systematic analysis. BMC Med 12: 145, 2014.

5. Sandhu BS and Sanyal AJ: Management of ascites in cirrhosis. Clin Liver Dis 9: 715-732, viii, 2005.

6. Runyon BA; AASLD Practice Guidelines Committee: Management of adult patients with ascites due to cirrhosis: An update. Hepatology 49: 2087-2107, 2009.

7. Planas R, Montoliu S, Ballesté B, Rivera M, Miquel M, Masnou H, Galeras JA, Giménez MD, Santos J, Cirera I, et al: Natural history of patients hospitalized for management of cirrhotic ascites. Clin Gastroenterol Hepatol 4: 1385-1394, 2006.

8. Salerno F, Cammà C, Enea M, Rössle M and Wong F: Transjugular intrahepatic portosystemic shunt for refractory ascites: A meta-analysis of individual patient data. Gastroenterology 133 825-834, 2007.

9. Garcia-Tsao G: Current management of the complications of cirrhosis and portal hypertension: Variceal hemorrhage, ascites, and spontaneous bacterial peritonitis. Gastroenterology 120 726-748, 2001

10. Sabri M, Saps M and Peters JM: Pathophysiology and management of pediatric ascites. Curr Gastroenterol Rep 5: 240-246, 2003.

11. Witte MH, Witte CL and Dumont AE: Progress in liver disease: Physiological factors involved in the causation of cirrhotic ascites. Gastroenterology 61: 742-750, 1971.

12. Levick JR and Michel CC: Microvascular fluid exchange and the revised Starling principle. Cardiovasc Res 87: 198-210, 2010.

13. Wongcharatrawee S and Garcia-Tsao G: Clinical management of ascites and its complications. Clin Liver Dis 5: 833-850, 2001

14. Schrier RW: Pathogenesis of sodium and water retention in high-output and low-output cardiac failure, nephrotic syndrome, cirrhosis, and pregnancy (2). N Engl J Med 319: 1127-1134, 1988

15. Levy M and Wexler MJ: Hepatic denervation alters first-phase urinary sodium excretion in dogs with cirrhosis. Am J Physiol 253: F664-F671, 1987.

16. Kostreva DR, Castaner A and Kampine JP: Reflex effects of hepatic baroreceptors on renal and cardiac sympathetic nerve activity. Am J Physiol 238: R390-R394, 1980.

17. Schrier RW, Arroyo V, Bernardi M, Epstein M, Henriksen JH and Rodés J: Peripheral arterial vasodilation hypothesis: A proposal for the initiation of renal sodium and water retention in cirrhosis. Hepatology 8: 1151-1157, 1988

18. Donati G, Piscaglia F, Coli L, Silvagni E, Righini R, Donati G, Pini P, Stefoni S and Bolondi L: Acute systemic, splanchnic and renal haemodynamic changes induced by molecular adsorbent recirculating system (MARS) treatment in patients with end-stage cirrhosis. Aliment Pharmacol Ther 26: 717-726, 2007.
19. Catalina MV, Barrio J, Anaya F, Salcedo M, Rincón D, Clemente G and Bañares R: Hepatic and systemic haemodynamic changes after MARS in patients with acute on chronic liver failure. Liver Int 23 (Suppl 3): S39-S43, 2003.

20. Jiang SM, Zhou GW, Shen C, Yan JQ, Wan L, Li QY, Yang WP, Shen BY, Chen H, Peng CH and Li HW: A clinical study on splanchnic hemodynamic changes after orthotopic liver transplantation for patients with portal hypertension. Zhonghua Wai Ke Za Zhi 46: 1699-1702, 2008 (In Chinese).

21. Helen MN and Newcomer ME: The structure of human retinol binding protein (RBP) with its carrier protein transthyretin reveals an interaction with the carboxy terminus of RBP. Biochemistry 38: 2647-2653, 1999.

22. Monaco HL, Rizzi M and Coda A: Structure of a complex of two plasma proteins: Transthyretin and retinol-binding protein. Science 268: 1039-1041, 1995.

23. Chantrel F, Agin A, Offner M, Koehl C, Moulin B and Hannedouche T: Comparison of cystatin $\mathrm{C}$ versus creatinine for detection of mild renal failure. Clin Nephrol 54: 374-381, 2000.

24. Fukui H, Saito H, Ueno Y, Uto H, Obara K, Sakaida I, Shibuya A Seike M, Nagoshi S, Segawa M, et al: Evidence-based clinical practice guidelines for liver cirrhosis 2015. J Gastroenterol 51: 629-650, 2016

25. European Association for the Study of the Liver: EASL clinical practice guidelines on the management of ascites, spontaneous bacterial peritonitis, and hepatorenal syndromeincirrhosis. J Hepatol 53: 397-417, 2010.

26. Delanaye P and Mariat C: The applicability of eGFR equations to different opulations. Nat Rev Nephrol 9: 513-522, 2013.

27. Ghassemi S and Garcia-Tsao G: Prevention and treatment of infections in patients with cirrhosis. Best Pract Res Clin Gastroenterol 21: 77-93, 2007.

28. Ozdamar SO, Gucer S and Tinaztepe K: Hepatitis-B virus associated nephropathies: A clinicopathological study in 14 children. Pediatr Nephrol 18: 23-28, 2003.

29. Trawalé JM, Paradis V, Rautou PE, Francoz C, Escolano S, Sallée M, Durand F, Valla D, Lebrec D and Moreau R: The spectrum of renal lesions in patients with cirrhosis: A clinicopathological study. Liver Int 30: 725-732, 2010

30. Zhou Y, Dong Q, Zhang R, Zhou S, Li L, Cheng K, Kong R, Yu Q, $\mathrm{Xu} \mathrm{S}, \mathrm{Li} \mathrm{J}$, et al: Cerebral hemodynamics and cognitive function in cirrhotic patients with hepatic encephalopathy. Gastroenterol Res Pract 2016: 8485032, 2016.

31. Xu L, Dai W, Li J, He L, Wang F, Xia Y, Chen K, Li S, Liu T, Lu J, et al: Methylation-regulated miR-124-1 suppresses tumorigenesis in hepatocellular carcinoma by targeting CASC3. Oncotarget 7: 26027-26041, 2016.

32. Yang J, Li J, Dai W, Wang F, Shen M, Chen K, Cheng P, Zhang Y, Wang C, Zhu R, et al: Golgi protein 73 as a biomarker for hepatocellular carcinoma: A diagnostic meta-analysis. Exp Ther Med 9: 1413-1420, 2015.

33. Liu Z, Wang J, Guo C and Fan X: microRNA-21 mediates epithelial-mesenchymal transition of human hepatocytes via PTEN/Akt pathway. Biomed Pharmacother 69: 24-28, 2015. 